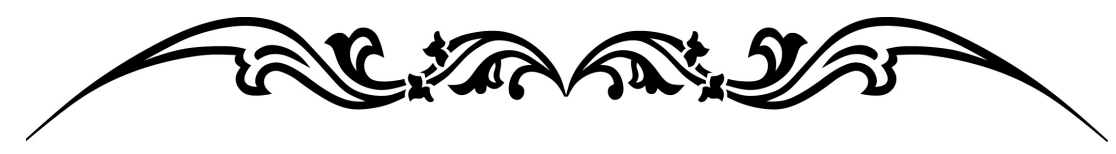

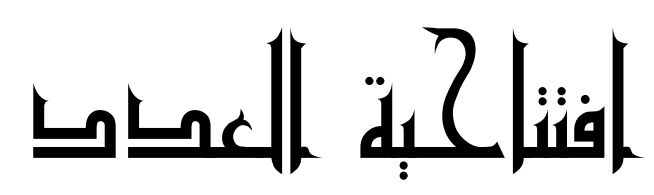

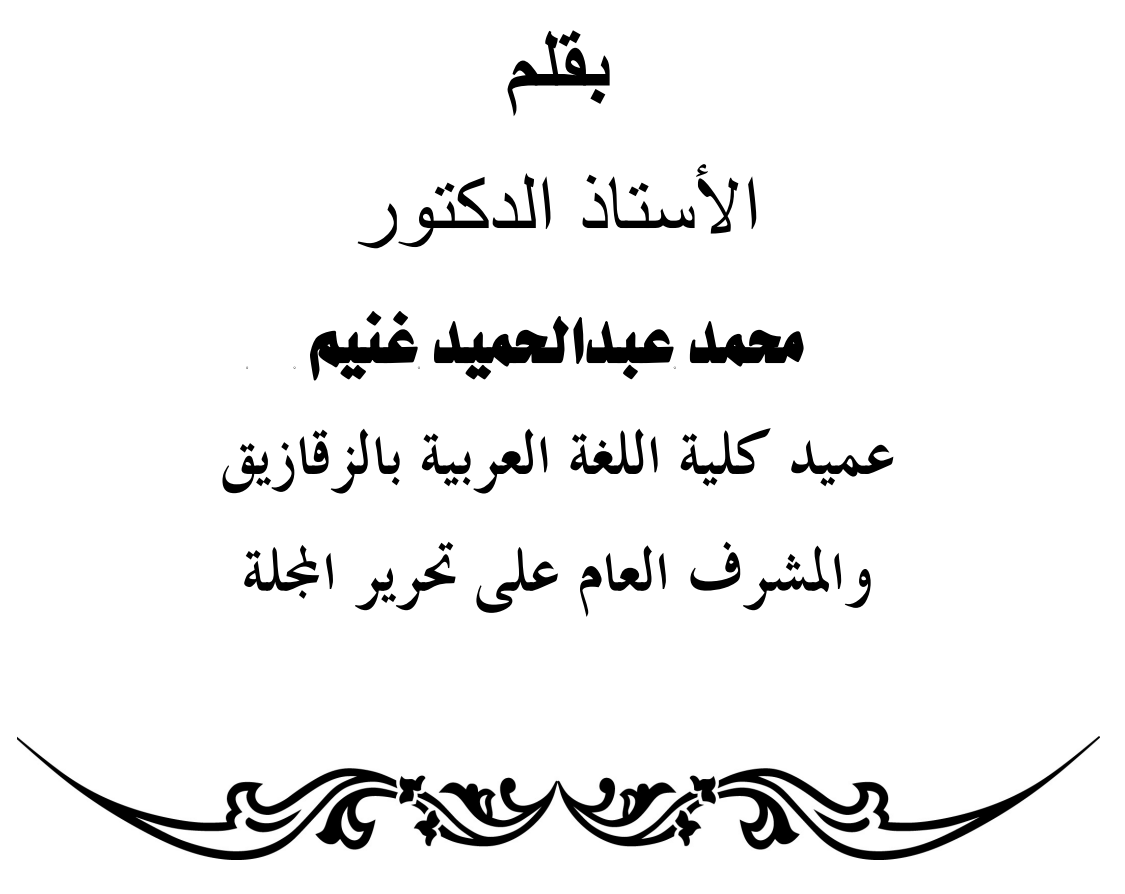


افتتاحية العدد

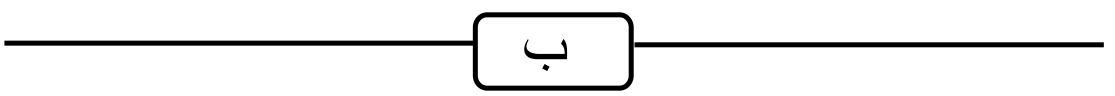




\section{اقتثتاحية العلد}

\section{بـ \\ الأستاذ الدكتور

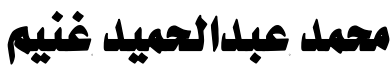

عميد كلية اللغة العربية بالزقازيق

والمثرف العام على تحرير الجلة

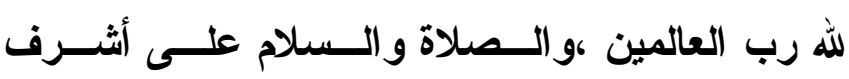

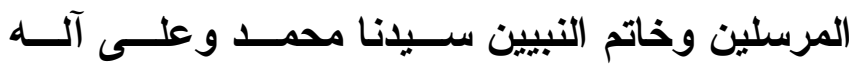

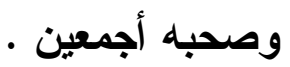

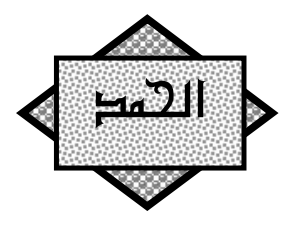

\section{وبعر 66، 6}

• فإن الله تعالى حين خلق الإسان واستخلصه لعمارة الأرض بنـى

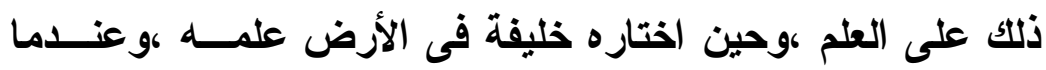
أرسل الوحى إلى رسولنا محمد (صلى الله عليه وسلم )كـان أول

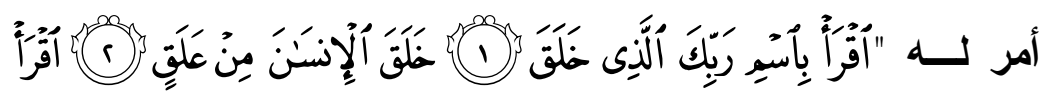

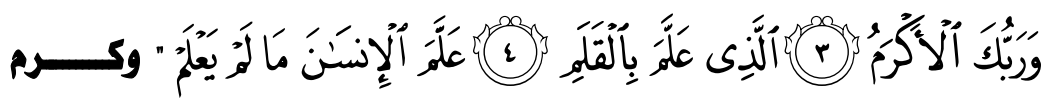

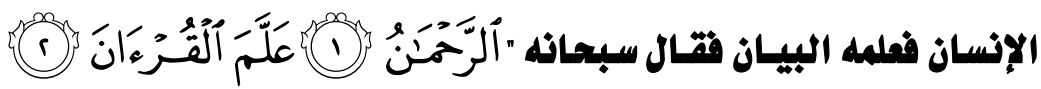

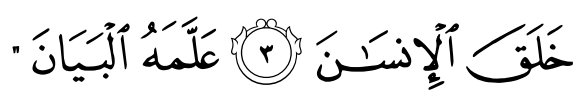
وجامعة الأزهر بعلمائها وباحثيها وطلابها منار ات هداية للعالمين فى مشارق الأرض ومغاربها . 
وكلية اللغة العربية بالزقازيق كلية جادة فى مجال البحث العلمـى منذ النشأة حتى وقتنا هذا و إلى مـــا شــاء الله بفـضـل باحثيهــا وعلمائها وأدبائها وناقديها ومحبيها من الباحثين من أنحاء العالم

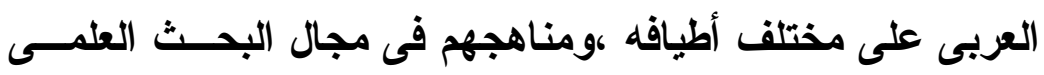
و الأدبى

وقد قدمت الكلية فى دوريتها السنوية ومؤتمر اتها مئات البحـوث الأدبية والعلمية فى مختلف مجالات العلم و المعرفة والثقافة ليتزود بها طلاب العلم والمعرفة كل فى مجال تخصصه . ومجلة الكلية فى عددها الجديد "الرابع والثلاثين " تقدم أكثر مسن خمسة وعشرين بحثا متنوعا فى مختلف التخصصات للباحثين من جامعة الأزهر ، ومن السعودية وسلطنة عمان و العراق. فقى مجال الدراسات الأدبية والنقدية تقدم الباحثون بخمسة بحوث متنوعة منها ما يعود بنا إلى التراث العربى كالبحث الأى تقدم به الاكتور/ فهز ابراهيم سعد البكر (سعودى الجنـسية ) بعنــوان " الكتابة المجلسية فى الأدب العربـ القديم ليـالى التوحيــى فــى الإمتاع والمؤانسة أنموذجا " ،وهو يتناول فيه آثرا أدبيــا أو فنـــا

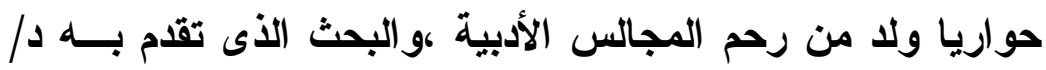
سعيد العسائى (عمانى الجنسية ) بعنوان "المخطوط الأدبى العمانى بين التحقيق والنشر " ،وهو يعرض لنا موضــوعا تر اثيــا حـــل المخطوطات الأدبية فى سلطنة عمان . ويتقدم إلينا د/ الثحات غمرى - (مصرى الجنسية )ببحــثـ حــول "أسس الحضارة الإسلامية فى شعر البهلانى "دراسة فى الإسـسان

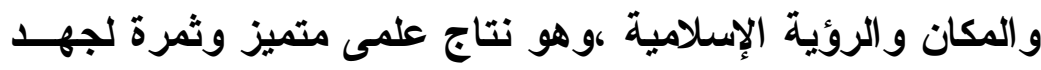


الباحث فى أثناء إعارته إلى دولة "زينجبار" وهو يكثف عن مدى الأثز الطيب للحضارة الإسلامية فى أفكار العالم الإسلامى.

وتقدمت الدكتورة /نسيمه بوصلاح (سعودية الجنسية ) بعنــوان " "(بينيستمولوجيا النص ومفهوم التكامل عند د /صابر عبدالـــديم ، ويعرض فيه لمنهجه النقدى التكاملى فى إظهار جماليات النــصى الأدبى ،وتقدم د/ حمود بن محمد (ســعودى ) بحــثـ بعـــوان : " صور الزهد فى رثاء الثيخ محمد العثيمين "وهو بحث جاد وجيا فى مضمونه ،وتقدم د/ محمد عبدالعزيز ببحث عن " رسائل أهـل فيل الأدلالس النبوية فى المضمون وقيم التشكيل الجمالى "وهى كلها بحوث جادة فى ميدان الدراسات الأدبية والنقدية وتعنى بالــشكل و المضمون و الأصالة و المعاصرة. وفى مجال الاراسـات البلاغية والنقدية تقــــم البــاحثون بأربعــة بحوث يدور معظمها حول الدراسات البلاغية القرآنية حيث شارك د/ سعيد الهلالهى ببحث تحت عنوان "من بلاغة القرآن فى وصــف عباد الرحمن فى سورة الفرقان " وهو بحث شائق وممتــع فـى عرض صفات عباد الرحمن ،وقدم د/ حنى التلاوى بحثا بعنوان

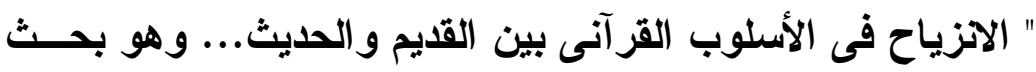
يجمع بين الأصالة والمعاصرة ،وقدمت الدكتورة / الجوهرة بنتت بخيت (سعودية ) بحثا بعنوان "موقف المستـشرقين النقـــاد مــن القرآن الكريم وإعجازه البلاغى ترجمــة ودراســـة " وهـــو مــن البحوث المهمة فى مجال الدراسات القرآنية التـى تكـشف عــن

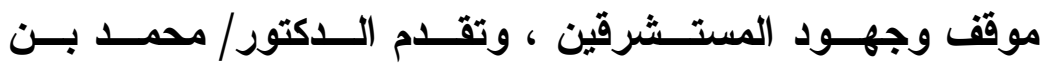
عبدالرحمن (سعودى ) ببحث بعنوان " أساليب الثرح والإيــضاح 
ومقاماتها فى التزبية والتوجيه دراسة بلاغية تطبيقية" وهو بحث مفيد فى مجاله حيث يعتنى بالقيم التربوية التى تمثل أهم الأسـس فى بناء القرد والمجتمع. وقدم د/ ،طلعت عبدالله بحثا بعنوان "البيان النبوى فــى حــديث الغلام والراهب والساحر - دراسة بلاغية تحليلية" وهو يكثف عن

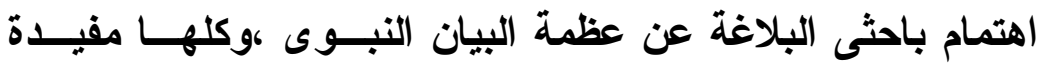
ومهمة فى مجال الار اسات البلاغية و النقدية . وفى مجال الاراسات اللغوية تقدم الباحثون بخمسة بحوث وكـــان للباحثين السعوديين النصيب الأكبر فى المشاركة حيث قدموا ثلاثة بحوث وهى بعنوان " آراء النيسابورى التصريفية فى كتابة بــاهر البرهان فى معانى مشكلات القرآن للاكتور / يوسف السلمى. وقدم د/ سليمان بن على الضحيان بحثا بعنوان "لامية الجمل لابن

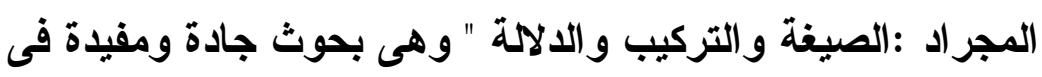
مجال الدراسات اللغوية وقدت الاكتورة/ هنية فتحى (مسصرية ) بحثا تحت عنوان "دور القراعات القرآنية فـى توجيــه ووضــع القواعد النحوية " وقدم د/ محمد عطية على عطية - بحثا بعنوان "ابـن الإثــبيلى

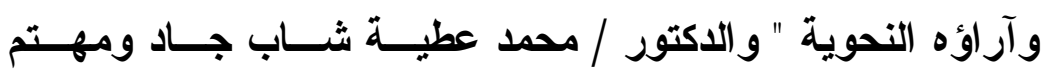
بقضايا التراث . وفى مجال أصول اللغة تقدم بحث واحـــ لواحـــ مــن البــاحثين الثباب الجادين بعنوان "مآثز الأوائل ومنطق الآواخر فى لهجـــة

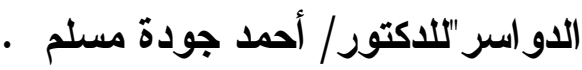


وفى مجال دراسات التاريخ والحضارة كان لباحثــات الـسعودية الاور الأعظم والنصيب الأوفى حيث تقدمن بخمسة بحـوث مــن

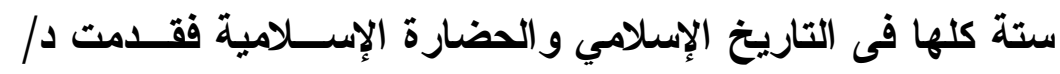
هيلة السـاهلى - بحثا بعنوان "الموقف فى الحـــارة الإســلامية

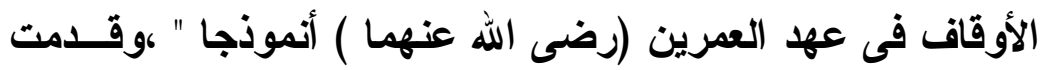
د/ منيرة بنت مرعث القحطانى بحثّا بعنوان : " حــوار الرســـول (ص ) مع الآخر فيىالدعوة إلى الإسلام " وما أحوجنا فـــ زمنتـــا هذا لمثل هذا البحث الأى يكثف عن عظمة الرسول (ص ) وعن سماحة الإسلام وقيمه الرفيعة .وقدم د/ ســارة العتيبـى بحثـــا بعنوان :" وصية معاوية بن أبى سفيان لابنه يزيد قبــلـ وفاتــه "

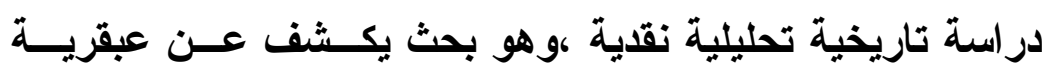
معاوية (رضى الله عنه ) وحكمته وسياسته ،وتقدمت د/ ريم بنت

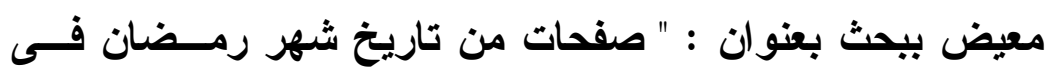
المدينة المنورة - دراسة فى العادات والتقاليا ،وهو يكثف عـن لـن القيم و المبادئ التى يعنى بها الإسلام فى حـــود صـــيح الــدين

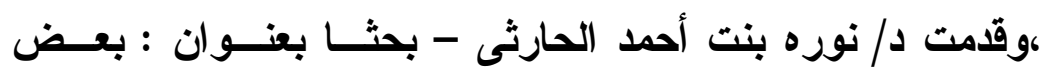
المؤلفات فى تيسير السيرة النبوية وتهذيبها ونظمها فى القـــنين الثامن والتاسع الهجريين " ،وهو بحث تاريخى يكثف عن اهتمام المؤرخين قديما بالسيرة النبوية الثريفة. وتقدم د/ عبدالرحمن عبدالحميا حماد (مسـرى ) ببحـث تحست

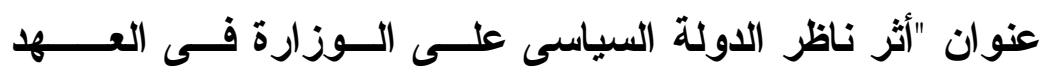
المملوكى " وهو من البحوث المهمة التى تكثف حقبة زمنية يخيم 
عليها كثير من الضبابية ،ودور الباحثين الجادين لكثف اللثام عن هذه الحقيقة .

وبعد ... فإننى أثنكر الباحثين الجادين على ما بذلوه مــن جهـــ

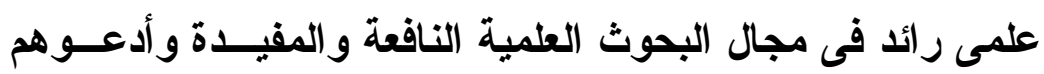

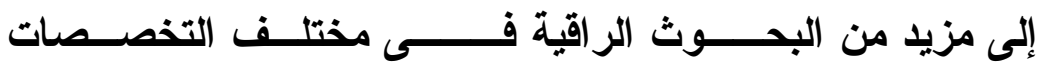
العلمية ،وأرجو من طلبة العلم والبــاحثين الإطـــلاع علــى هــــه

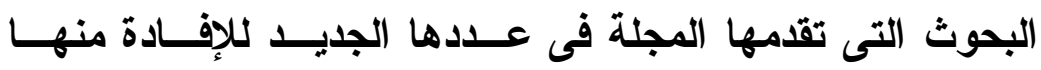
و التأسي بها.

والله الموفق والهادى إلي سواء السبيل وما توفيقى إلا بالله عليه تلوكلت التوفيق والسداد إليه أنيب

أ. د/ هحمهد عبدالحهميد غنيهم عمبد الكلية ورئيس التحريز 